Arq. Bras. Med. Vet. Zootec., v.61, n.1, p.104-109, 2009

\title{
Efeito da centrifugação sobre a qualidade do sêmen canino
}

\author{
[Effect of centrifugation on quality of canine semen] \\ I.C.N. Cunha ${ }^{1}$, M.D. Lopes $^{2}$ \\ ${ }^{1}$ Universidade Estadual do Norte Fluminense \\ Avenida Alberto Lamego, 2000 \\ 28013600 - Campos dos Goytacazes, RJ \\ ${ }^{2}$ Faculdade de Medicina Veterinária e Zootecnia - UNESP - Botucatu, SP
}

\section{RESUMO}

Avaliou-se o efeito da centrifugação sobre a viabilidade do sêmen canino e compararam-se três meios de diluição pré-centrifugação. Utilizaram-se 10 ejaculados completos de 10 cães que, após a avaliação inicial, foram divididos em quatro porções (grupos). Uma das amostras, não centrifugada, formou o grupo-controle; as outras foram diluídas em três diferentes meios e centrifugadas a $800 \mathrm{x}$ g por 15 minutos, formando os grupos: CPSA - constituído por sêmen centrifugado em plasma seminal autólogo; CLG - sêmen centrifugado em meio à base de leite desnatado e glicose (LG); e CPer- sêmen centrifugado em gradientes de Percoll (45\% e 90\%). Após a centrifugação e a eliminação do sobrenadante, procedeu-se à ressuspensão de todas as porções do ejaculado em LG e à imediata avaliação quanto à motilidade, vigor, aglutinação espermática e integridade das membranas espermáticas. Todas as suspensões foram, então, incubadas a $37^{\circ} \mathrm{C}$ por 30 minutos e reavaliadas. $\mathrm{O}$ processo de centrifugação não causou danos aos espermatozoides e a centrifugação em meio LG melhorou a viabilidade espermática.

Palavras-chave: cão, sêmen, centrifugação, diluidor

\begin{abstract}
The effect of the centrifugation process on canine sperm viability was evaluated using three different precentrifugation extenders in the process. After an initial evaluation, ten complete ejaculates from ten dogs were used and subdivided in four groups. One sample of semen was not centrifuged and was used as control and the remaining samples of semen were diluted in three different extenders and centrifuged at $800 \times \mathrm{g}$ per 15 minutes, performing groups: CPSA-centrifuged in autologous seminal fluid, CLGcentrifuged in skim milk plus glucose extender $(L G)$, and CPer-centrifuged under Percoll gradient $45 \%$ and $90 \%$ ). After centrifugation, the resulting pellets were diluted in $L G$ and evaluated for motility, viability, sperm agglutination, and spermatic membrane integrity. All the samples were incubated at $37^{\circ} \mathrm{C}$ for 30 minutes and the evaluations were performed again. Centrifugation procedures did not induce damage to canine spermatozoa and samples centrifuged and diluted in skim milk plus glucose extender remained with better viability.
\end{abstract}

Keywords: dog, semen, centrifugation, extenders

\section{INTRODUÇ̃̃O}

Os ejaculados caninos apresentam variações significativas de volume e concentração espermática devido, principalmente, às diferenças entre portes e raças (Di Santis et al., 2001). A centrifugação é uma das formas utilizadas para uniformizar essas variações e manter constantes o volume e a concentração espermática, sem que se observe influência negativa sobre as células espermáticas (Lopes e Papa, 1998). Em alguns protocolos de criopreservação, a centrifugação tem sido utilizada como forma de eliminar a primeira e a

Recebido em 8 de outubro de 2007 
terceira frações do sêmen de cães (Rijasseleare et al., 2002; Oliveira et al., 2006), no entanto, ela pode remover fatores inibidores da capacitação e prostaglandinas presentes no plasma seminal (Carrell et al., 1998).

England e Allen (1992) verificaram efeito deletério da primeira e da terceira frações do ejaculado canino sobre as características espermáticas. Explicaram, ainda, que na cobrição natural, o tempo de contato do espermatozoide com essas frações é pequeno, diminuindo esse efeito. Os mesmos autores pesquisaram o efeito da incubação dos espermatozoides caninos diluídos na primeira e terceira frações do ejaculado e verificaram declínio no número de espermatozoides morfologicamente normais, decorrentes dos efeitos deletérios dessas frações.

Rota et al. (1995) descreveram os efeitos prejudiciais do plasma seminal sobre a membrana plasmática dos espermatozoides e sugeriram que a adição de diluidores ao sêmen aumentaria o número de células espermáticas com membrana plasmática íntegra. Jasko (1994) sugeriu que vários diluidores podem ser utilizados para pré-diluir o sêmen para a centrifugação e que esse passo garante boa proteção à célula espermática durante esse processo. $\mathrm{O}$ autor recomendou a utilização de um meio diluidor à base de leite desnatado para a realização de tal procedimento.

Técnicas avançadas de preparo dos espermatozoides, incluindo swin-up, swin-down, diferentes gradientes de centrifugação com Percoll e colunas de Sephadex e de Ficoll têm sido utilizados para selecionar espermatozoides móveis no sêmen. Lopes e Papa (1998) afirmaram que a centrifugação do sêmen canino em Ficoll-Paque melhora significativamente os resultados de congelação e de descongelação em meio à base de glicina-gema.

O Percoll é uma suspensão coloidal de polivinilpirrolidina (PVP) ligada à sílica e esta ligação reduz as propriedades tóxicas do gel de sílica. A maior vantagem do Percoll é não penetrar em membranas biológicas e, além disso, possuir baixa viscosidade e osmolaridade. Devido ao grande tamanho de suas partículas, a centrifugação em velocidades moderadas pode gerar um gradiente de densidade próprio (Gennis, 1989).
Prakash et al. (1998) sugeriram que a exposição ao Percoll protege os espermatozoides da produção excessiva de radicais livres, que podem ser produzidos durante centrifugação, causando alterações nas funções da membrana, induzindo a peroxidação lipídica.

O objetivo deste trabalho foi verificar os efeitos do processo de centrifugação no sêmen canino e comparar a pré-diluição do sêmen em meio à base de leite desnatado e glicose, Percoll ou plasma seminal autólogo na realização desse procedimento.

\section{MATERIAL E MÉTODOS}

Após a realização do exame clínico detalhado, da coleta de sangue para o hemograma e para a pesquisa de brucelose e leptospirose e da coleta de sêmen para exame andrológico, foram selecionados de 10 cães adultos, saudáveis, sendo cinco animais sem raça definida, com peso entre 10 e $20 \mathrm{~kg}$, provenientes do biotério central da UNESP - Botucatu, e cinco da raça Cocker Spaniel, com pesos entre 15 e $20 \mathrm{~kg}$, provenientes de criatórios particulares. Os animais provenientes do biotério foram mantidos em canis com solário durante a fase de coleta do sêmen, os de criatórios particulares permaneceram em seus respectivos canis.

Um ejaculado completo de cada cão, coletado por estimulação manual do pênis, foi recolhido em um funil plástico acoplado a um tubo de coleta graduado e mantido a $37^{\circ} \mathrm{C}$ para imediatas avaliações macro e microscópicas. A motilidade e o vigor espermáticos e a ocorrência de aglutinação espermática foram avaliados sob microscopia de contraste de fase. A motilidade foi expressa em porcentagem (0-100) e o vigor por um escore, que variou de 0 a 5 (Manual ..., 1996). A ocorrência de aglutinação espermática foi descrita por meio de um escore que variou de 0 a 3, em que: 0 - ausência de aglutinação; 1 aglutinações esparsas, visualizadas em campos isolados; 2 - aglutinações esparsas, observadas em todos os campos e 3 - aglutinações frequentes, em todos os campos.

Para avaliação da integridade das membranas utilizou-se a associação do iodeto de propídio e carboxifluoresceína (Harrison e Vickers, 1990) modificada, na qual $10 \mu \mathrm{L}$ de sêmen foram 


\section{Cunha et al.}

acrescidos de $40 \mu \mathrm{L}$ da solução de trabalho composta de: $960 \mu \mathrm{L}$ de solução de citrato de sódio a $3 \% ; 10 \mu \mathrm{L}$ solução de iodeto de propídio $(10 \mathrm{mg}$ de iodeto de propídio $+20 \mathrm{~mL}$ solução fisiológica); $20 \mu \mathrm{L}$ solução de carboxifluoresceina $(9,2 \mathrm{mg}$ carboxifluoresceína + 20mL DMSO); $10 \mu \mathrm{L}$ solução 1:80 de formalina a $40 \%$. As amostras foram avaliadas sob iluminação epifluorescente (400x). Foram contadas 100 células espermáticas e classificadas como íntegras as células emitindo fluorescência verde, e como lesadas as células com o núcleo emitindo fluorescência vermelha.

Após a avaliação inicial das características espermáticas, os ejaculados foram divididos em quatro porções (grupos) iguais e transferidos para tubos plásticos de centrífuga, graduados. Uma das amostras, não centrifugada, foi mantida em banho-maria a $37^{\circ} \mathrm{C}$ e constituiu o grupo-controle (NC). As outras três porções foram diluídas em: plasma seminal autólogo, formando o grupo CPSA; meio à base de leite desnatado e glicose (CG; Kenney et al., 1975), formando o grupo CCG; e gradientes de Percoll (45\% e 90\%), formando o grupo CPer. Após a centrifugação a $800 \mathrm{x}$ g por $15 \mathrm{~min}$ e descarte do sobrenadante, retirou-se de $10 \mu \mathrm{L}$ do pélete para a avaliação da integridade da membrana espermática. Os péletes foram ressuspendidos em $2 \mathrm{~mL}$ de $\mathrm{LG}$. A mesma quantidade do diluidor $\mathrm{LG}$ foi acrescido ao grupo $\mathrm{NC}$, e todos os grupos foram avaliados quanto à motilidade e vigor espermático. As amostras foram então incubadas em banho-maria a $37^{\circ} \mathrm{C}$ por $30 \mathrm{~min}$ e novamente avaliadas. Todas as avaliações, em todos os grupos, ocorreram em dois momentos: logo após a centrifugação e após incubação em banho-maria a $37^{\circ} \mathrm{C}$ por 30 minutos.
Realizaram-se análises preliminares para verificar a consistência dos dados e estatística descritiva para se obter médias, desvios-padrão e verificar a normalidade dos dados. Como a característica porcentagem de células íntegras não apresentou distribuição normal, usou-se a transformação angular (arc sen $\sqrt{ } \%$ ), pois as respostas percentuais apresentaram-se entre valor mínimo de zero e valor máximo de 100 (Sampaio, 2007). Ao final, foi realizada a análise de variância considerando-se os efeitos fixos de grupo e momento sobre as características motilidade, vigor e porcentagem de células íntegras.

\section{RESULTADOS E DISCUSSÃO}

Após o processo de centrifugação, os valores das amostras centrifugadas e não centrifugadas do sêmen e acrescidas do diluidor não diferiram entre si quanto à motilidade e vigor (Tab. 1 e 2). No entanto, mesmo tendo sido verificada queda de motilidade em todos os grupos após 30 minutos de incubação a $37^{\circ} \mathrm{C}$, nos grupos em que se realizou a centrifugação, verificou-se maior motilidade e vigor em relação ao grupo-controle. Os resultados confirmaram os já obtidos por outros autores e sugerem que o plasma seminal é potencialmente deletério à integridade espermática (England e Allen, 1992) e, que a centrifugação é um método eficaz para retirada do plasma seminal e padronização do volume e concentração de sêmen de cães (Lopes e Papa, 1998; Rijasseleare et al., 2002).

No grupo CPer, verificou-se grande quantidade de espermatozoides com aglutinação cabeçacabeça, mesmo após a diluição e incubação por 30 minutos em extensor à base de leite desnatado e glicose a $37^{\circ} \mathrm{C}$.

Tabela 1. Motilidade espermática (\%) do sêmen de cães, de acordo com os grupos, após centrifugação e incubação

\begin{tabular}{lcc}
\hline \multicolumn{1}{c}{ Grupo } & $\begin{array}{c}\text { Após } \\
\text { centrifugação }\end{array}$ & $\begin{array}{c}\text { Após 30min } \\
\text { de incubação }\end{array}$ \\
\hline Não centrifugado & $71 \mathrm{aA}$ & $47 \mathrm{aB}$ \\
Centrifugado em PSA & $79 \mathrm{aA}$ & $61 \mathrm{bB}$ \\
Centrifugado em LG & $79 \mathrm{aA}$ & $67 \mathrm{bB}$ \\
Centrifugado em Percoll & $74 \mathrm{aA}$ & $63 \mathrm{bB}$ \\
\hline
\end{tabular}

$\mathrm{PSA}=$ plasma seminal autólogo; $\mathrm{LG}=$ meio à base de leite desnatado e glicose.

Letras distintas, maiúsculas na linha ou minúsculas na coluna, indicam diferença entre os valores $(\mathrm{P}<0,05)$. 
Tabela 2. Vigor espermático (escore de 0-5) do sêmen de cães, de acordo com os grupos, após centrifugação e incubação

\begin{tabular}{lcc}
\multicolumn{1}{c}{ Grupo } & $\begin{array}{c}\text { Após } \\
\text { centrifugação }\end{array}$ & $\begin{array}{c}\text { Após } \\
30 \mathrm{~min} \\
\text { de } \\
\text { incubação }\end{array}$ \\
\hline Não centrifugado & $3,2 \mathrm{aA}$ & $2,0 \mathrm{aB}$ \\
Centrifugado em PSA & $3,7 \mathrm{aA}$ & $2,7 \mathrm{abB}$ \\
Centrifugado em LG & $3,8 \mathrm{aA}$ & $3,1 \mathrm{bB}$ \\
Centrifugado em & $3,5 \mathrm{aA}$ & $3,0 \mathrm{bA}$ \\
Percoll & &
\end{tabular}

PSA $=$ plasma seminal autólogo; $\mathrm{LG}=$ meio á base de leite desnatado e glicose.

Letras distintas, maiúsculas na linha ou minúsculas na coluna, indicam diferença entre os valores $(\mathrm{P}<0,05)$.

Sabendo-se que o potencial elétrico da membrana, que se reflete como uma característica de carga elétrica positiva ou negativa à membrana externa do espermatozoide, pode ser alterado pelos radicais de hidrato de carbono ligados a lipídios e proteínas constituintes da membrana (Amann e Graham, 1993), e que essas ligações podem se desfazer com certa facilidade (Gennis, 1989), sugere-se que o Percoll possa ter eliminado esses radicais glicosilados ligados à membrana espermática, promovendo alterações de cargas elétricas das células espermáticas. Como consequência, as células espermáticas podem ter se agregado umas às outras na dependência das características de repulsão ou de atração de cargas elétricas presentes em sua superfície externa.
Sugere-se, ainda, que a retirada total do plasma seminal das células espermáticas pode não ser benéfica à manutenção da capacidade fertilizante dos espermatozoides, fato já citado por Vianna et al. (2002), que trabalharam com sêmen equino e propuseram a manutenção de apenas uma parte de plasma seminal autólogo ou, ainda, de proteínas concentradas adicionadas no extensor utilizado para a ressuspensão do sêmen, após o processo de centrifugação. Nothling et al. (2005) concluíram que o plasma seminal autólogo adicionado ao sêmen canino pósdescongelamento, aparentemente, exerce efeito específico sobre os espermatozoides, promovendo aumento da fertilidade após a inseminação intravaginal.

No NC, a capacidade de manutenção do vigor após incubação foi menor (Tab. 2), no entanto, deve-se ressaltar que não houve diferença entre o vigor neste grupo e naquele centrifugado em plasma seminal autólogo (CPSA), no mesmo momento de avaliação. Resultados similares foram citados por England e Allen (1992). No grupo onde foi utilizado $\mathrm{CPer}$, o vigor não se alterou após a incubação. No entanto, neste mesmo grupo, verificou-se, também, aglutinação espermática após a incubação (Tab. 3), fato que pode ser considerado prejudicial à fertilidade, visto que a motilidade retilínea e progressiva é necessária para a fertilização.

Tabela 3. Valores da aglutinação espermática do sêmen de cães, de acordo com os grupos, após centrifugação e incubação

\begin{tabular}{lcc}
\multicolumn{1}{c}{ Grupo } & $\begin{array}{c}\text { Após } \\
\text { centrifugação }\end{array}$ & $\begin{array}{c}\text { Após 30min } \\
\text { de incubação }\end{array}$ \\
\hline Não centrifugado & $0 \mathrm{~A}$ & $0 \mathrm{~A}$ \\
Centrifugado em PSA & $0 \mathrm{~A}$ & $1,5 \mathrm{~B}$ \\
Centrifugado em LG & $0 \mathrm{~A}$ & $0 \mathrm{~A}$ \\
Centrifugado em Percoll & $0 \mathrm{~A}$ & $1,5 \mathrm{~B}$ \\
\hline
\end{tabular}

PSA = plasma seminal autólogo; $\mathrm{LG}=$ meio á base de leite desnatado e glicose.

Letras diferentes na linha indicam diferença entre os valores $(\mathrm{P}<0,05)$.

Não se verificaram alterações da integridade de membranas resultante do procedimento de centrifugação (Tab. 4), semelhante ao resultado verificado por England e Allen (1992). Rijasseleare et al. (2002) incubaram sêmen canino a $5^{\circ} \mathrm{C}$ por 72 horas e só conseguiram detectar alterações na integridade da membrana dos espermatozoides centrifugados após 48 horas de refrigeração a $5^{\circ} \mathrm{C}$. Esses autores sugeriram que alguns efeitos subletais sobre a membrana só podem ser verificados após um determinado período de incubação, assim, se o tempo de incubação tivesse sido maior, esses efeitos subletais poderiam ter sido detectados. 


\section{Cunha et al.}

Tabela 4. Médias transformada em arc sen $\sqrt{\mathrm{x}}(\mathrm{em} \mathrm{rad})$ e original (\%) de células espermáticas íntegras do sêmen de cães, de acordo com os grupos, após centrifugação e incubação

\begin{tabular}{lccc}
\hline Grupo & $\begin{array}{c}\text { Média } \\
\text { transformada }\end{array}$ & Desvio-padrão & $\begin{array}{c}\text { Média } \\
\text { original }\end{array}$ \\
\hline Não centrifugado & $1,38 \mathrm{a}$ & 0,155 & 98,2 \\
Centrifugado em PSA & $1,43 \mathrm{a}$ & 0,141 & 99,0 \\
Centrifugado em LG & $1,41 \mathrm{a}$ & 0,190 & 98,7 \\
Centrifugado em Percoll & $1,38 \mathrm{a}$ & 0,151 & 98,2 \\
\hline
\end{tabular}

$\mathrm{PSA}=$ plasma seminal autólogo; $\mathrm{LG}=$ meio á base de leite desnatado e glicose.

Não houve diferença entre os valores $(\mathrm{P}>0,05)$.

Provavelmente, as composições dos diluidores de centrifugação utilizados proporcionaram maior atividade tampão, atividade antioxidante, controle da osmolaridade, substrato para metabolismo ou, ainda, promoveram a retirada de substâncias nocivas presentes no plasma seminal, proporcionando a manutenção do vigor espermático por um período mais longo. Rijasselaere et al. (2002) verificaram que a adição TRIS-gema durante a centrifugação conferiu maior resistência aos espermatozoides, aumentando sua capacidade de resistir ao estresse da centrifugação.

Verificaram-se maiores valores de motilidade e vigor quando o sêmen foi centrifugado (Tab. 1 e 2) e não foi observada ocorrência de aglutinação após incubação quando esta foi realizada em presença de diluidor à base de leite desnatado e glicose (Tab. 3). Assim, os dados analisados sugerem que o diluidor à base de leite desnatado e glicose proporcionou aumento da proteção aos espermatozoides após centrifugação e incubação por 30 minutos a $37^{\circ} \mathrm{C}$.

Conclui-se que a remoção do plasma seminal por meio da centrifugação não induz efeitos deletérios nas características seminais analisadas e que a adição de um diluidor à base de leite desnatado e glicose, durante o processo, pode ser uma alternativa viável para a eliminação do plasma seminal, prolongando a sobrevida dos espermatozoides e preservando viabilidade necessária para a fertilização.

\section{REFERÊNCIAS BIBLIOGRÁFICAS}

AMANN, R.P.; GRAHAM, J.K. Spermatozoal function In: Equine reproduction. Philadelphia: Lea \& Febiger, 1993.

CARRELL, D.T.; KUNECK, P.H.; PETERSON, C.M. et al. A randomized, prospective analysis of five sperm preparation techniques before intrauterine insemination of husband sperm. Fertil. Steril., v.69, p.122-126, 1998.

DI SANTIS, G.W.; AMORIM, R.L.; BANDARRA, E.P. Aspectos clínicos e morfológicos das alterações prostáticas em cães - revisão. Rev. Educ. Contin. CRMV-SP, v.4, p.46-52, 2001.

ENGLAND, G.C.W.; ALLEN, W.E. Factors affecting the viability of canine spermatozoa II: Effects of seminal plasma and blood. Theriogenology, v.37, p.373-381, 1992.

GENNIS, R.B. Biomembranes: molecular structure and function. New York: Springer, 1989. 533p.

HARRISON, R.A.P.; VICKERS, S.E. Use of fluorescent probes to asses membrane integrity in mammalian spermatozoa. J. Reprod. Fertil., v.88, p.343-352, 1990.

JASKO, D.J. Procedures for cooling and freezing of equine semen. Ars Vet., v.10, p.156-165, 1994.

KENNEY, R.M.; BERGMAN, R.V.; COOPER, W.L. et al. Minimal contamination techniques for breeding mares: technique and preliminary findings. In: ANNUAL CONVENTION AMERICAN ASSOCIATION EQUINE PRACTITIONERS 21., 1975, Boston. Proceedings... Boston, 1975. p.327

LOPES, M.D.; PAPA, F.O. Effects of different diluents and method of centrifugation for freeze canine semen In: CONGRESS OF THE WORDL SMALL ANIMAL VETERINARY ASSOCIATION, 23., 1998, Buenos Aires. Proceedings... Buenos Aires, 1998. p.799.

MANUAL para exame andrológico e avaliação de sêmen animal. Belo Horizonte: CBRA, 1996. $65 \mathrm{p}$. 
NOTHLING, J.O.; SHUTTLEWORTH, R.; de HAAS, K. et al. Homologous prostatic fluid added to frozen-thawed dog spermatozoa prior to intravaginal insemination of bitches resulted in better fertility than albumine-free TALP. Theriogenology, v.63, p.1469-1480, 2005.

OLIVEIRA, E.C.S.; JULIANI, G.C.; MARQUES Jr., A.P. et al. In vitro evaluation of canine spermatozoa cryopreserved in different extenders. Arq. Bras. Med. Vet. Zootec., v.58, p.1116-1122, 2006.

PRAKASH, P.; LEYKIN, L.; CHEN, Z. et al. Preparation by differential gradient centrifugation is better than swim-up in selecting sperm with normal morphology (strict criteria). Fertil. Steril., v.69, p.722-734, 1998.
RIJASSELAERE, T.; VAN SOOM, A.; MAES, D. et al. Effect of centrifugation on in vitro survavil of fresh diluted spermatozoa. Theriogenology, v.57, p.1669-1681, 2002.

ROTA, A.; STRÖM B.; LINDE-FORSBERG, C. Effects of seminal plasma and three extenders on canine semen stored at $4^{\circ} \mathrm{C}$. Theriogenology, v.44, p.885-900, 1995.

SAMPAIO, I.B.M. Estatística aplicada à experimentação animal. Belo Horizonte: FEPMVZ, 2007. 264p.

VIANNA, S.A.B.; SOUZA, G.V.; FAGUNDES, $B$. et al. Influência do plasma seminal na congelabilidade de sêmen equino. Rev. Bras. Reprod. Anim., v.26, p.179-181, 2002. 